modulate components of the immune response, particularly those causing tissue destruction, are important and should be pursued.

$$
\begin{array}{r}
\text { GILLIAN AINSLIE } \\
\text { ERIC BATEMAN } \\
\text { Respiratory Clinic, } \\
\text { Groote Schuur Hospital, }
\end{array}
$$$$
7925 \text { Cape, South Africa }
$$

Variability of inspired oxygen concentration with nasal cannulas

The paper by Dr EA Bazuaye and others (August 1992;47:609-11) on inspired oxygen concentrations from nasal cannulas ("prongs") is welcome. The potential hazards of nasal oxygen are underappreciated, as we found when asking junior medical staff how they use oxygen during exacerbations of chronic ventilatory failure. This inquiry followed a particularly spectacular example of "prong poisoning," where nasal oxygen at 1 litre per minute delivered an $\mathrm{FiO}_{2}$ conservatively estimated at $40 \%$.' Nearly half the doctors we asked thought nasal oxygen was as good as or better than Venturi mask in these circumstances, and only one appreciated that nasal cannulas deliver an $\mathrm{FIO}_{2}$ which can rise as respiratory failure worsens and ventilation falls. Our case supports the suggestion of Dr Bazuaye and colleagues that nasal cannulas may be more hazardous during acute exacerbations of ventilatory failure, and sustains their statement that nasal cannulas are "unsatisfactory if precise control of inspired oxygen is desired." R J O DAVIES Osler Chest Unit Churchill Hospital, Oxford $O X 3 \mathrm{Z}$

1 Davies RJO, Hopkin JM. Nasal oxygen in exacerbations of ventilatory failure, an
underappreciated risk. $B M J 1989 ; 299: 43-4$.

\section{Randomised clinical trial of chest} drainage systems

We should like to comment on the article by Dr ANJ Graham and others (June 1992;47461-2). The study sample consisted of only postoperative cases, though the authors have extended the recommendation of a Portex drain to trauma and emergencies where the risk of tube blockage is higher and low pressure negative suction is invariably required.' In selecting their sample the authors have excluded patients who would require suction, but in the discussion they have analysed the requirement of suction in two groups. This would be a major confounding factor in the study. The reasons for reduction in "time to sitting" and in morbidity with a Portex drain, although drainage with bottles was adequate, are not discussed. As the drainage systems were not "blind" and there was variable encouragement for mobilisation by the nursing staft, there is scope for a bias for mobilisation of the two study groups and thus in the observations. The major factors in the early mobility of patients and discharge would be the type of underlying and associated illness and complications. Con- sidering the requirement of suction and the possibility that Portex tubes can fall out, the authors' recommendations need further evaluation.

Department of Pulmonary Medicine, Postgraduate Institute of Medical Education and Research, Chandigarh-160 012, India

1 Harriss DR, Graham TR. Management of intercostal drains. Br J Hosp Med 1991;45:383-6.

AUTHORS' REPLY We thank Dr Sarniak for showing interest in our paper. His assertion that chest drains inserted after thoracic trauma invariably require suction is not, in fact, supported by the reference he cites. In our experience this is necessary only in cases of persistent pneumothorax, usually because of a massive air leak.' Pleural suction is not readily available at the roadside or battlefield and the advantages that drainage bags have over underwater seals in these circumstances are obvious. This is supported by recent military experience in wartime conditions. ${ }^{2}$

Patients were not entered into the trial if it was known that postoperative pleural suction would be essential. Randomised patients who subsequently required suction were retained in the study and the results were analysed according to the intended treatment. This is an accepted method for reducing bias in this type of clinical trial. ${ }^{3}$

There are inherent difficulties in carrying out a trial comparing such different methods of treatment. It was not possible to perform a blind study. Nevertheless, we believe that it is important to attempt to assess different techniques in a randomised fashion rather than basing management on uninformed opinion and speculation. The fact that drainage bags were found to be safe when used after elective surgery, which is in effect a form of thoracic rauma, should give clinicians the confidence to use them, when required, in emergency conditions.

A N J GRAHAM JA McGUIGAN Northern Ireland Regiona Thoracic Surgical Department, Royal Victoria Hospital Belfast BT12 6BA

1 McManus KG, McGuigan JA. Management of chest injuries. Bailiere's Clinical Anaesthesiology 1992;6:349-80.

2 Williams JG, Riley TDR, Moody RA. Resuscitation experience in the Falkland Islands campaign. BMJ 1983;286:775-7.

3 Altman DG. Clinical trials. In: Altman DG, ed. Practical statistics for medical research. London: Chapman and Hall, 1991:440-77.

\section{Barcelona's asthma epidemics}

With regard to Dr C Picado's “For Discussion" paper (March 1992;47:197-200), we propose that exogenous 15-lipoxygenase enzyme from soybean modulates the severity of the asthma response in soybean induced asthma, since soybean is the world's riches known source of lipoxygenase enzyme and is causal in epidemic asthma with the unusual clinical features described by Dr Picado.

Plant lipoxygenases are common in nature and could readily be aerosolised during the bulk handling of dry soybean. After antigen challenge a product of the 15-lipoxygenase pathway of arachidonic acid metabolismnamely, 15(S)-hydroxy-5,8,11-cis-13-transeicosatetraenoic acid (15-HETE)-is observed in large amounts in bronchoalveolar lavage fluid from patients with chronic stable asthma. Eosinophil suspensions incubated with ionophore and granulocytes when stimulated in the presence of 15-HETE produce lipoxin $A_{4}{ }^{\prime}$ A characteristic of asthma is the presence of eosinophils in bronchial exudates. Lee et al have found lipoxin $\mathrm{A}_{4}$ in the bronchoalveolar lavage fluid in human pulmonary disease. ${ }^{2}$ Lipoxin $A_{4}$ elicits constriction of the guinea pig lung strip, is chemotactic and chemokinetic in response to leucocytes, and may further regulate arachidonic acid release. Lai et al showed that preinhalation of 15-HETE increased the early asthma response in atopic individuals by $39 \%$, with no late response, after stimulation by antigen. ${ }^{3}$ It is therefore likely that the exacerbation of the asthmatic response seen after the inhalation of soybean dust is due to the excessive production of lipoxins or related products. We submit that the magnitude of that response is due to the exogenous enzyme. The clinical features in the Barcelona epidemics that support this hypothesis are: sudden onset, severity, and rapid recovery; augmentation of the early asthma response and no late phase response; and a lack of clinical reproducibility with standard methods of antigen challenge.

Dr Picado's paper provides the clinical observations necessary to describe a novel human disease mechanism whereby exogenous lipoxygenase enzymes may gain access to human substrates and modulate pathophysiological responses.

ANDREW JUDD 120 Wilson Crescent, Saskatoon, Saskatchewan,
S7J $2 L 5$

JOHN DOCHERTY Division of Cardiovascular Sciences, St Boniface General Hospital Research Centre, University of Manitoba Faculty of Medicine, University of Manitoba Faculty of Medicine, 351 Tache Avenue,
Winnipeg, Canada R2H $2 A 6$

1 Serhan CN, Samuelsson B. Lipoxins: a new series of eicosanoids (biosynthesis, stereochemistry, and biological activities). $A d v$ Exp Med Biol 1988;229:1-14.

2 Lee TH, Crea AE, Gant, Spur BW. Identification of lipoxin A4 and its relationship to the sulfidopeptide leukotrienes $\mathrm{C4}, \mathrm{D} 4$, and E4 in the bronchoalveolar lavage fluids obtained from patients with selected pulmonary diseases. Am Rev Respir Dis 1990;141:1453-8.

3 Lai CKW, Polosa R, Holgate ST. Effect of 15 (S)-hydroxyeicosatetraenoic acid on allergeninduced asthmatic responses. Am Rev Respir Dis 1990;141:1423-7.

\section{NOTICE}

Latin American conference on cystic fibrosis

The fifth Latin American Cystic Fibrosis Conference is to take place in Recife, Brazil, on 3-7 April 1993. Further information can be obtained from Dr Fernando de Abreu e Silva, Rua Duque de Caxias 1327/101, Porto Alegre RS, Brazil 90010 (fax (081) 421.2404). 